Volume 8. No. 8, August 2020

International Journal of Emerging Trends in Engineering Research

Available Online at http://www.warse.org/IJETER/static/pdf/file/ijeter40882020.pdf

https://doi.org/10.30534/ijeter/2020/40882020

\title{
Android Mobile Augmented Reality Application for 3D Visualization of Museum Collectibles in Surakarta
}

\author{
Heru Supriyono ${ }^{1}$, Muhammad Wildan Hanani ${ }^{2}$, Andrea Yahya ${ }^{2}$ \\ ${ }^{1}$ Department of Electrical Engineering, Universitas Muhammadiyah Surakarta, Indonesia, \\ Heru.Supriyono@ums.ac.id \\ ${ }^{2}$ Department of Informatics, Universitas Muhammadiyah Surakarta, Indonesia, L200150016@ student.ums.ac.id, \\ L200150013@student.ums.ac.id.
}

\begin{abstract}
This article discusses the process of developing and perceptional validation by prospective users of the augmented reality application on mobile devices for three-dimensional (3D) visualization of museum collectibles. The main purpose of this publication is to visualize museum collection objects in 3D models on Android mobile devices so that visitors could be able to see collections from all sides. Augmented reality application displays a 3D model by scanning a unique marker for every collection. The test results showed that the application worked properly on smartphones using Android 4.0 or later version and with a minimum of $1 \mathrm{~GB}$ of memory in low-light room condition or brighter. Moreover, test results on various markers conditions indicated that the application could still be able to read the marker and display a 3D model with the marker condition that was crossed out with a ballpoint or there were traces of the folded line. In addition, if the marker was covered with a solid object such as paper with a maximum of $40 \%$, the marker was still readable by the application. The results of the perceptual evaluation by users showed that the average of acceptance rate was $82.282 \%$ at the Nusantara Keris Museum and $88.47 \%$ at the Surakarta Cultural Heritage Museum.
\end{abstract}

Key words : Android application, augmented reality, museum collectible, $3 \mathrm{D}$ visualization.

\section{INTRODUCTION}

The city of Surakarta is an old city in the heart of Central Java Province where the kingdom of Surakarta Hadiningrat Sunanate was established before the founding of the Republic of Indonesia. With that history, in Surakarta City there are many historical relics such as the palace and other relics. Heritage and relics are stored in museums located in the city of Surakarta, including the Nusantara Keris Museum and the Surakarta Cultural Heritage Museum.

Keris was a knife-like traditional weapon in the past for Javanese people in particular. The Nusantara Keris Museum holds hundreds of traditional weapons collections from various regions in Indonesia, including 400 traditional weapons, most of which are keris and spears originating from Java, while the remaining small portion are traditional weapons from outside Java. Most of the keris collections are stored in a glass cabinet so that they can be seen from one side only which causes visitors not be able to see objects from all sides directly. Surakarta Cultural Heritage Museum has 13 exhibition rooms where each room contains different types of collections. Some of the collections are including weapons, arts, tools, statues, kitchen equipments, ceremonial tools, traditional conveyances and much more. The same as at Nusantara Keris Museum, most collections are kept tightly in a glass cabinet so that visitors find it difficult to see the overall collection of objects.

The use of 3D modeling technology makes it possible to study structure, technology, and enable to simulate an object as a whole virtually [1] for any real object. The 3D modeling technology gives the sensation to feel the object entirely and enable to see the overall texture for its users. One of technologies used for 3D modeling is Augmented reality (AR) technology. Since its introduction, AR has attracted the attention of researchers to be applied in broad fields. In the education, research results showed that AR can enhance the experience and motivation of students in understanding special events that require three-dimensional visualization [2] and also, in turn, able to facilitate correcting misconception of scientific concepts among the students [3]. Moreover, the research results showed that AR potentially to be used in learning history [4] or learning history and tourism altogether because it was possible to visualize the legacy of history virtually in $3 \mathrm{D}[5]$.

The next potential application of AR was in the area of tourism such as reported in [6] where AR applications were used to enhance the experience of tourists when visiting cultural heritage spots in Bali. The use of AR technology also potentially improves interaction between tourists and the environment when applied for urban tourism [7]. Still for urban tourism, AR technology improves tourist experiences for presenting related information such as tourist attraction, shop, and restaurant [8]. 
Heru Supriyono et al., International Journal of Emerging Trends in Engineering Research, 8(8), August 2020, 4293 - 4300

AR technology has been proposed to be applied to a museum aimed at improving the experience of visitors in accordance with their needs, for example, in guiding systems to replace printed material-based directions [9]. AR technology was also reported to be able to improve visitor experience, namely to visualize $3 \mathrm{D}$ models of available collection objects so that visitors feel more enjoy and able to increase the number of visitors, especially among children and students compared to when there was no AR technology [10]. Apart from enjoying it more, the AR application was also reported to be able to enhance the experience of museum visitors in terms of learning which was shown by visitors being able to answer questions about collection objects correctly more than if without AR [11]. AR technology has also been reported to be able to visualize existing museum objects [12].

In addition to visualizing collection objects in 3D models, AR technology was also reported to be used to provide additional information such as in the form of labels on virtual collection objects in the learning process when implemented in a human anatomy museum [13]. In relation to museum tourism activities, in terms of business, in addition to enhancing the experience for visitors, AR technology has also reported influencing the desire of tourists to buy things even at higher prices [14].

Based on these research results, AR technology has the potential to be applied to the Nusantara Keris Museum and Surakarta Cultural Heritage Museum. This article discusses the AR application design process on Android mobile devices to display 3D models of collection objects in the two museums and the user evaluation process. The purposes of this publication are: (1) to visualize museum collection objects in a 3D model using AR technology on Android smartphone applications and (2) to unveil the user's perception of the developed application.

\section{METHOD}

The research was conducted in two phases. The first phase was the development of 3D models and its viewer application with AR technology on Android smartphones while the second phase was perceptual evaluation by users of the use of applications that have been developed. There were two applications which have been developed for two museums. Applications on smartphones were developed using the System Development Life Cycle (SDLC) waterfall method which has several stages including requirements analysis, data collection, coding, testing and implementation [15].

\subsection{Requirement Analysis}

Based on the requirement analysis conducted, it can be seen that the Nusantara Keris Museum and Surakarta Cultural Heritage Museum require AR applications on mobile devices such as smartphones and tablets that can display 3D models of museum collection objects. In order to enhance user's experience for all visitors, the proposed AR application considered elements of engagement suggested in [16]. Marker based AR technology was used where each object to be visualized was represented by a unique marker that is different from markers for other objects. The proposed application has one actor only and has three main functionalities as presented in Figure 1.

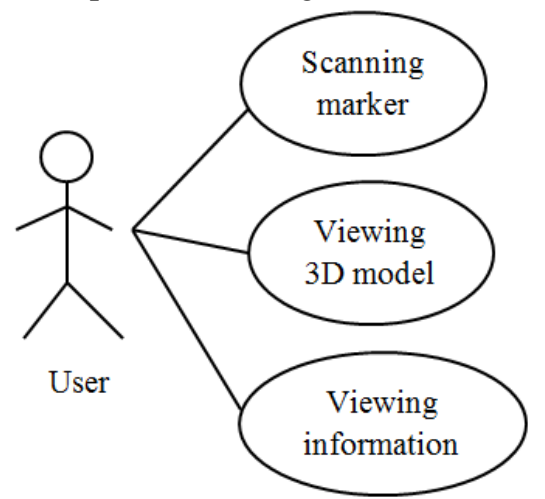

Figure 1: Use Case Diagram Representing Actor and Functions of the Application

User has to scan the predetermined marker using application in order to bring up the 3D model on a smartphone or tablet. The marker was placed near the glass cabinet where the collection was stored so that visitors would be able to scan the marker more easily for the desired collection object. In addition, markers were also printed on museum collection books so that visitors would be able to see 3D models of museum collection objects without having to be near the collection objects. Collection books which are equipped with markers are very useful if there are many visitors who thronged the museum so that it is not possible to scan markers placed near the collection to see 3D models.

Data needed in the development of the AR application includes detailed information about collections in the museum and photographs of the collection from all sides. Detailed information about collectibles was obtained from literature and interviews with informants, namely museum employees who handle the history of collectibles, including information of its usefulness, manufacture period and manufacture year. Collections in the Nusantara Keris Museum can be identified from the physical form that is whether it is curved and if there are curves so that how many curves there are. Due to the abundance collections, only 10 collection from the Nusantara Keris Museum which represent all items have been chosen to be built of their 3D models. Collections of objects at the Surakarta Cultural Heritage Museum which are hundreds of item have very diverse physical shapes. Therefore, in this article only 10 objects which are the main collections of the museum were chosen to make the 3D models. 


\subsection{Constructing 3D Model and Coding}

At the stage of 3D models construction and coding, sets of softwares were used including: Blender, Unity 3D, Vuforia SDK, Android Studio, and Mozilla Firefox. First of all, 3D models of museum collection objects were built by using Blender. After that, markers for each object were created and then registered to Vuforia. Finally, the computing process on an AR application was developed by using Android studio. The overall computational stages carried out by the AR application can be seen in Figure 2.

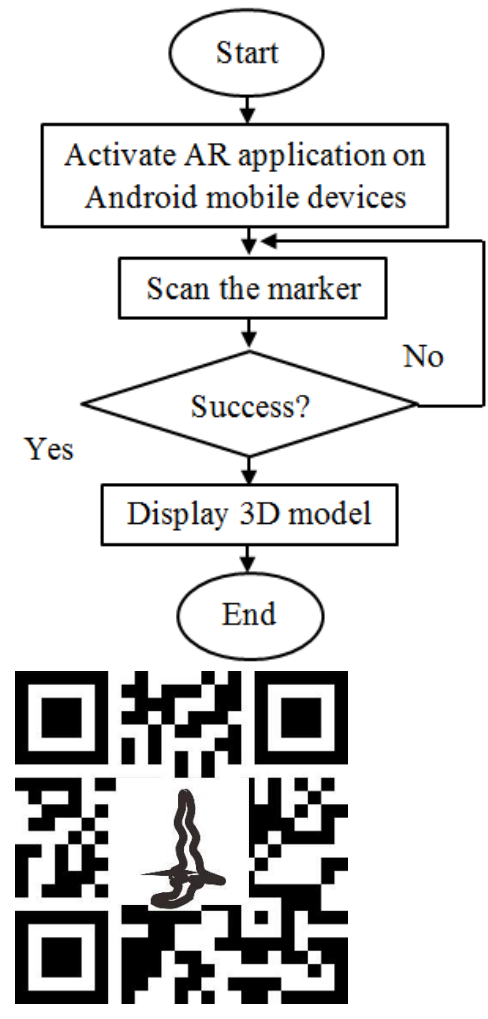

(a)
Figure 2: Flowchart Showing Computation Process of AR Application

First, the user must activate the application on an Android smartphone. Then, the application will activate the camera to scan marker for the collection object to be displayed. After the camera successfully scanned the marker, the application will display the 3D model according to the marker. If the user wants to display another object, the user can replace the current marker with the new one to be scanned so that the application will display the new 3D object. Exit button is for exit the application.

\section{RESULTS AND DISCUSSION}

\subsection{Mobile Android Application Obtained}

The obtained AR application program was in an *.apk extension file which can be installed on Android mobile devices or smartphones. Figure 3 shows a sample of resulted marker and its corresponding 3D model.

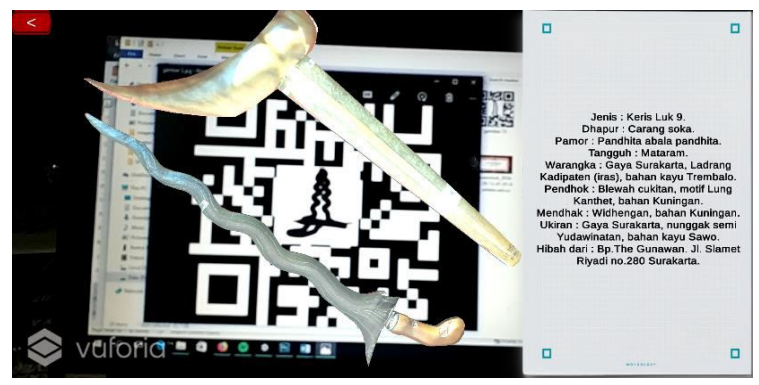

(b)

Figure 3: (a) A sample of Marker, (b) Correspond 3D Model Displayed by the AR Application After Successfully Scanning Marker where There was a 3D Model Display and Detailed Information to the Right of the 3D Model (a keris display made for Nusantara Keris Museum)

Markers can be in the form of images, text or text with a variety of unique patterns. In this article, markers were made in black and white which have QR-code-like patterns as shown in Figure 3 (a). Markers were printed on sticker paper so that they can be affixed to a place near the corresponding collection objects and also was printed on the book of museum collectibles so that it could be scanned easier. After the AR application on Android mobile device was activated and the marker was successfully scanned, the AR application bring up the 3D model display as depicted in Figure 3(b). Furthermore, the 3D model displayed in the AR application can be rotated by tapping the screen with two fingers and rotated as needed so that users can see the $3 \mathrm{D}$ object from all sides which were not possible done by visitors to the collection object directly.

\subsection{Blackbox Testing}

After the AR application has been completed, then it was tested with namely black box testing to see whether the proposed application was running properly as expected. Black box testing itself is a testing that concerned about how the outputs and responses are generated from inputs and conditions at the time of execution [17]. Black box testing was performed on an AR application which has been installed on an Android mobile device. The Black box test results shown in Table 1 suggested that all functions of AR application were running well as expected.

Table 1: Black box testing results of AR application 
Heru Supriyono et al., International Journal of Emerging Trends in Engineering Research, 8(8), August 2020, 4293 - 4300

\begin{tabular}{|c|c|c|c|}
\hline Tested Function & Testing Activity & Expectation & Result \\
\hline Starting application & $\begin{array}{c}\text { Pressing button AR application } \\
\text { on Android smartphone }\end{array}$ & Application was activated & Valid \\
\hline Displaying 3D model & Scanning marker & $\begin{array}{c}\text { Application scanned the marker and displayed the 3D } \\
\text { model in accordance with the scanned marker }\end{array}$ & Valid \\
\hline Displaying 3D model & $\begin{array}{c}\text { Rotating 3D model on AR } \\
\text { application }\end{array}$ & $\begin{array}{c}\text { 3D model was rotated displaying intended other sides } \\
\text { view }\end{array}$ & Valid \\
\hline Displaying 3D model & $\begin{array}{c}\text { Changing the marker } \\
\text { Another 3D model in accordance with the scanned } \\
\text { marker }\end{array}$ & Valid \\
\hline Finishing application & $\begin{array}{c}\text { Pressing "X" button of AR } \\
\text { application }\end{array}$ & Application was finished & Valid \\
\hline
\end{tabular}

\subsection{Testing on Various Mobile Devices which Have Different Specifications}

Testing the performance of AR application on mobile devices that have different specifications was done because there are high probability that museum visitors use various mobile devices with different specifications. The test results are shown in Table 2.

Table 2: Test results on smartphones with different technical specifications

\begin{tabular}{|c|c|c|}
\hline Device & Technical Specification & Testing Results \\
\hline 1 & $\begin{array}{c}\text { Android 4.2.2, RAM 1 GB/ } \\
\text { ROM 8 GB }\end{array}$ & Working properly \\
\hline 2 & $\begin{array}{c}\text { Android 5.1.1, RAM 2 } \\
\text { GB/ROM 16 GB }\end{array}$ & Working properly \\
\hline 3 & $\begin{array}{c}\text { Android 7.1.1, RAM 3 } \\
\text { GB/ROM 32 GB }\end{array}$ & Working properly \\
\hline 4 & $\begin{array}{c}\text { Android 8.1, RAM 4 GB/ROM } \\
\text { GB }\end{array}$ & Working properly \\
\hline 5 & $\begin{array}{c}\text { Android 5.0.2, RAM 2 } \\
\text { GB/ROM 16 GB }\end{array}$ & Working properly \\
\hline 6 & $\begin{array}{c}\text { Android 7.0, RAM 3 GB/ROM } \\
32 \text { GB }\end{array}$ & Working properly \\
\hline 7 & $\begin{array}{c}\text { Android 9.0, RAM 3 GB/ROM } \\
32 \text { GB }\end{array}$ & Working properly \\
\hline
\end{tabular}

Mobile device specifications were characterized by the type of Android operating system used, the size of random access memory (RAM) and the capacity of read only memory (ROM). Testing was done by installing the developed application on smartphones that were popular and widely used by the people of Surakarta city and surrounding areas. Based on the direct observation it was found that the smartphone used by people now has an Android operating system of at least 4.0 (Jellybean series) with RAM size of 1 GB and ROM capacity of 8 GB. The test results presented in
Table 2 suggested that the developed AR application worked well for all seven smartphones used for testing.

\subsection{Testing for the Effect of Room Lighting}

Testing for the effect of room lighting was done to model the lighting conditions in the actual museum space where the AR application would be implemented. Testing was performed in an indoor environment to model the actual condition that all museum collectibles were exhibited inside the museum rooms. The testing process was done by running the AR application and scanning markers inside a room where the lighting condition was adjustable. Lighting conditions were grouped in qualitative levels to model the real museum conditions. The test results outlined in Table 3 showed that the AR application can only scan markers and display 3D models if the room was in dim or brighter condition while for dark or very dark condition the AR application cannot read the marker unless the user turns on the torch feature of the smartphone.

Table 3: The results marker reading test due to the effect of lighting conditions

\begin{tabular}{|c|c|}
\hline Lighting condition & Results \\
\hline Very bright & Marker was scanned successfully \\
\hline Bright & Marker was scanned successfully \\
\hline Dim & Marker was scanned successfully \\
\hline Dark & Marker could not be scanned \\
\hline Very dark & Marker could not be scanned \\
\hline
\end{tabular}

\subsection{Testing by Giving Streaks on the Marker}

Tests were done by giving lines crossing on the marker using a ballpoint so that the black and white pattern on the marker is streaked. The test results presented in Figure 4 showed that although there were streaks on the marker as long as they do not damage the entire marker image the AR application can still be able to read the marker and display the 3D object. 


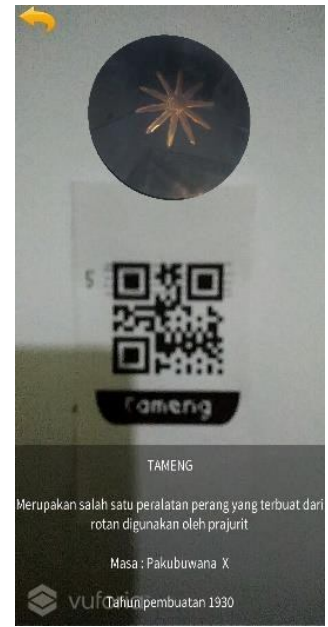

(a)

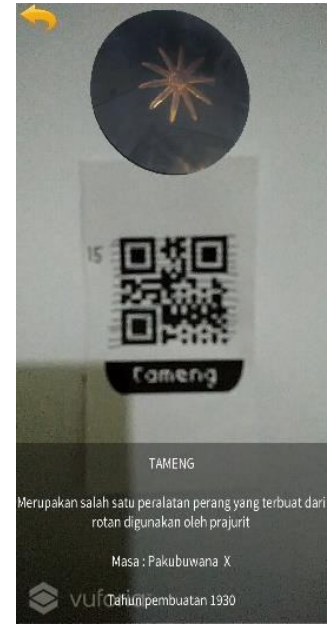

(b)

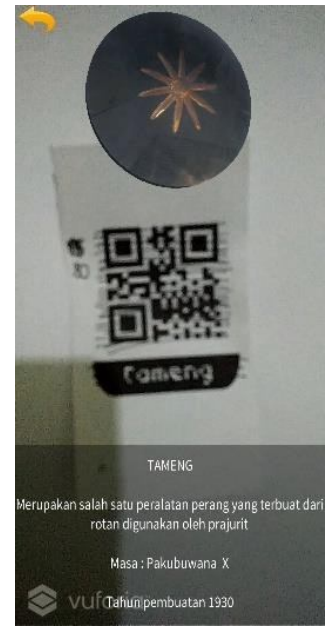

(c)

Figure 4: Test Results for Marker Condition with Streaks, (a) 5 Streaks, (b) 15 Streaks, (c) 30 Streaks

\subsection{Test With pre-Folded Marker}

This test was carried out to model if the marker or book collections of museum objects were folded so that markers inside of it were also folded. The folds on the marker provide line tracing on it. The test results for up to four folds on the marker suggested that although there were traces of the fold but if it does not damage the overall marker pattern then the AR application can still read the marker and display the 3D object properly. In testing with a squeezed marker, it showed that the AR application could not read the marker anymore because when the marker was re-stretched again, there were too many fold lines that damage the marker pattern.

\subsection{Testing for Partially Covered Marker}

The test was carried out to model the conditions where the marker was covered by solid objects for example paper. The test results by closing the marker with the paper shown in Figure 5 indicated that the AR application can still read the marker and display the 3D model if the marker was covered with a maximum of approximately $40 \%$. If the marker was covered more than $40 \%$ then the AR application can no longer read the marker.

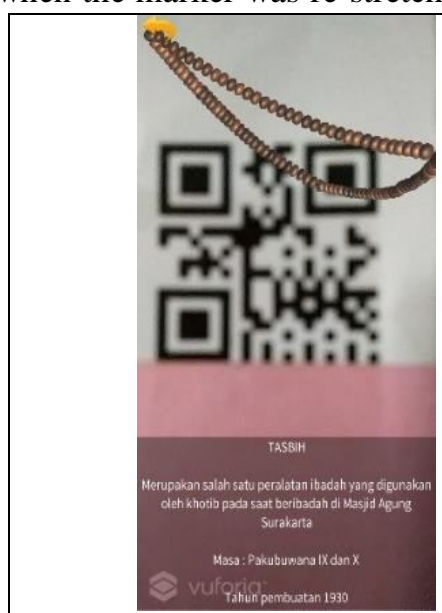

(a)

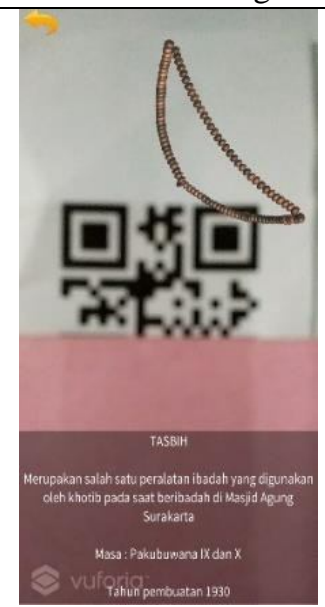

(b)

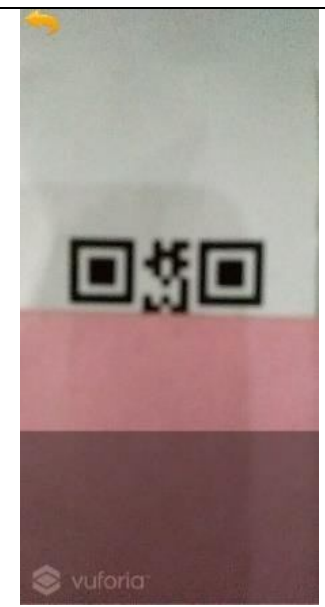

(c)

Figure 5: Test Results for Marker was Covered by Paper, (a) 20\%, (b) 40\%, (c) 60\%

\subsection{Perspectual Evaluation by Users}

Evaluation of developed AR application by users was used to find out perceptual responses from users about the proposed application. Respondents of the test were taken from museum visitors with the criteria still in a young age that was the estimated age between 15 and 50 years because in this range of age most likely users were very often using various applications on mobile devices, especially smartphones. The respondents were randomly selected from museum visitors regardless the gender and then asked them to try the AR application that was developed on markers that had been prepared either marker on the exhibited collections or in the provided collection books. Then, users who have tried the AR application were asked to fill out a questionnaire which has been prepared in advance. Testing of user perceptions using 
Heru Supriyono et al., International Journal of Emerging Trends in Engineering Research, 8(8), August 2020, 4293 - 4300

questionnaires were also done extensively by previous researchers, for example in [18] when testing the level of user appreciation on an AR application developed for cultural heritage.

Users were asked to fill out a questionnaire by giving perception that was expressed in likert scale with five levels of agreement namely Strongly Agree (SA) has a weight of 5, Agree (A) has a weight of 4, Neutral (N) has a weight of 3, Disagree (D) has a weight of 2, and Strongly Disagree (SD) has a weight of 1 . From each answered statement from all respondents, the final result score in the form of a percentage value was then calculated by using equation 1 and equation 2 like was done by previous researchers such as in [19].

$$
\begin{aligned}
& P=\frac{\sum \text { Score }}{\text { MaximumScore }} \times 100 \% \\
& \text { MaximumScore }=N \times 5
\end{aligned}
$$

where $\mathrm{P}$ was the perception value in percent, $\sum$ Score is the weighted sum of likert scale answers of all respondents and $\mathrm{N}$ is the total number of respondents. Tests were carried out in two places namely Nusantara Keris Museum and Surakarta Cultural Heritage Museum.

There were 35 respondents participating in the test at Nusantara Keris Museum. In the questionnaire, there were five statements to answer by giving the degree of approval according to the likert scale. The test results can be seen in Table 4.

Table 4: The results of user evaluation tests conducted at the Nusantara Keris Museum

\begin{tabular}{|c|c|c|c|c|c|c|c|}
\hline Statement & \multicolumn{4}{|c|}{ Answer } & $\sum$ Score & \multirow{2}{*}{ P } \\
\cline { 2 - 6 } & SD & D & N & A & SA & & \\
\hline All functions in the application run well & 0 & 0 & 4 & 20 & 11 & 147 & $84.00 \%$ \\
\hline This application is easy to use & 0 & 0 & 2 & 22 & 11 & 149 & $85.14 \%$ \\
\hline This application has an attractive appearance for users & 0 & 1 & 8 & 19 & 7 & 137 & $78.28 \%$ \\
\hline This application can help the public to see keris in more detail & 0 & 0 & 4 & 22 & 9 & 145 & $82.85 \%$ \\
\hline This application can attract public interest to visit Nusantara Keris Museum & 0 & 1 & 3 & 24 & 7 & 142 & $81.14 \%$ \\
\hline Average & & & & & & & $82.28 \%$. \\
\hline
\end{tabular}

The test results presented in Table 2 showed that the average perception result was $82.282 \%$ with the highest perception value was $85.14 \%$ for statement "this application is easy to use". The statement "all functions can work well" has the second highest perception value that was getting $84 \%$. Furthermore, the statement "application has an attractive appearance" got perception value of $78.28 \%$ where this was the lowest perception value of all statements where there was one respondent who disagree with this statement. The statement "this application can help people see more details about the keris" get $82.85 \%$ while the statement "this application can attract people to visit the Nusantara Keris Museum", received $81.14 \%$. This testing data suggested that the developed AR application received positive perception from visitors which can be summarised that this application was easy to use, can help people see more details about the keris, and can increase people's interest in being able to visit the Nusantara Keris Museum. However, perceptional testing results indicated that there was still some shortcomings in the application, for example in terms of appearance attractiveness which has the lowest perception value.

Testing carried out at Surakarta Cultural Heritage Museum was participated by 31 respondents chosen randomly. The same as for testing at Nusantara Keris Museum, results of filling out the questionnaire by visitors were then calculated by using formulas (1) and (2) whose results are shown in Table 3.

\begin{tabular}{|c|c|c|c|c|c|c|c|}
\hline \multirow[t]{2}{*}{ Statement } & \multicolumn{5}{|c|}{ Answer } & \multirow{2}{*}{$\sum$ Score } & \multirow[t]{2}{*}{$\mathbf{P}$} \\
\hline & SD & D & $\mathbf{N}$ & $\mathbf{A}$ & SA & & \\
\hline Application is easy to understand and use & 0 & 0 & 0 & 15 & 16 & 140 & $90.32 \%$ \\
\hline The function can work well & 0 & 0 & 1 & 16 & 14 & 137 & $88.38 \%$ \\
\hline Attractive application display & 0 & 0 & 4 & 13 & 14 & 134 & $86.45 \%$ \\
\hline Can see collection objects from various sides & 0 & 0 & 1 & 10 & 20 & 143 & $92.25 \%$ \\
\hline $\begin{array}{l}\text { Can attract the interest of people visiting the } \\
\text { museum }\end{array}$ & 0 & 0 & 4 & 13 & 14 & 134 & $86.45 \%$ \\
\hline Application is required and is suitable to use & 0 & 0 & 1 & 17 & 13 & 136 & $87.74 \%$ \\
\hline Are you satisfied with this application? & 0 & 0 & 1 & 17 & 13 & 136 & $87.74 \%$ \\
\hline Average & & & & & & & $88.47 \%$ \\
\hline
\end{tabular}

Table 5: Evaluation by users tests results conducted at Surakarta Cultural Heritage Museum

Data from the questionnaire test results in Table 5 showed

that the average of perception value of all statements was 
Heru Supriyono et al., International Journal of Emerging Trends in Engineering Research, 8(8), August 2020, 4293 - 4300

$88.47 \%$ with the highest perceptual value in the statement "can see collectibles from various sides" i.e. got perception of $92.25 \%$ while the lowest value is in the statement of "interesting application display" and "Can attract the interest of people visiting the museum" each of which gets a perception value of $86.45 \%$. These data showed that this application was feasible to be used to support tourism activities at Surakarta Cultural Heritage Museum. User perceptual test results carried out at Nusantara Keris Museum and Surakarta Cultural Heritage Museum suggested that visitors have positive perceptions about the AR application and implicitly indicated that the AR application was able to enhance the visitor experiences. These results of user evaluations are in line with the results of studies reported by other researchers for example in [20].

\subsection{Potential Obstacles Still Faced}

The attractiveness display of the proposed application is still relatively low. Next research should focus on this area because, as applied for websites, the attractiveness display of an application will increase interest of users [21]. Also, the software quality model could be applied to predict its reliability [22] or to predict if there is a defect in the application [23]. In this article, the developed AR application combines application and 3D model data in one *.apk application file so that the built application has a very large file size. The application file size for each museum was 150 MB for 10 museum collection objects, whereas in total there are hundreds of collection objects for each museum, so that the estimated file size can reach more than 5 GB if all 3D models of collectible objects are included. This condition is of course very impractical because visitors must install an AR application program on their smartphone so that it can cause the memory of the smartphone to be filled up. In addition, because visitors must download applications from the internet, the costs incurred will be large enough if the internet data are provided by the museum or if visitors use their own internet data so that it would be burdening visitors.

\section{CONCLUSION}

In this article, an augmented reality mobile application has been developed for visualizing museum collectibles in 3D. As a prototype, the application has been implemented in two museums in Surakarta city. The test results showed that the application worked well for all smartphones with different specifications used in the experiment. Also, the application was able to read the marker and display the 3D model when the marker was given streaks, pre-folded or covered by solid object on some level. The results of perceptional evaluations to prospective users, namely the randomly selected museum visitors showed that the average level of acceptance was $82.282 \%$ for Nusantara Keris Museum and $88.47 \%$ for
Surakarta Cultural Heritage Museum. These results were very positive so that if it were truly implemented in the museums it could enhance the visitor's experience because it could visualize collectible objects in 3D from all sides which so far cannot be done when only looking at the collection objects on display directly. Considering weaknesses of the proposed application, future works should be focused in some areas such as increasing the attractiveness of the display, enhancing software quality to predict both reliability and defect and also develop system architecture in order to decrease its file size.

\section{REFERENCES}

1. D. Dedov, M. Krasnyanskiy, A. Obukhov and A. Arkhipov. Design and development of adaptive simulators using 3D modeling, International Journal of Applied Engineering Research, vol. 12, no. 20, pp. 10415-10422, 2017.

2. J. M. Gutiérrez and M. D. M. Fernández. Augmented Reality Environments in Learning, Communicational and Professional Contexts in Higher Education, Digital Education Review, vol. 26, pp. 22-35, December 2014.

3. D. N. E. Phon, A. F. Z. Abidin, M. F. A. Razak, S. Kasim, A. H. Basori and T. Sutikno. Augmented Reality: Effect on Conceptual Change of Scientific, Bulletin of Electrical Engineering and Informatics, vol. 8, no. 4, pp. 1537-1544, December 2019.

4. N. H. M. Azhar, N. M. Diah, S. Ahmad, and M. Ismail. Development of Augmented Reality to Learn History, Bulletin of Electrical Engineering and Informatics, vol. 8, no. 4, pp. 1425-1432, December 2019. https://doi.org/10.11591/eei.v8i4.1635

5. J. Kysela and P. Štorková. Using Augmented Reality as a Medium for Teaching History and Tourism, Procedia Social and Behavioral Sciences, vol. 174, pp. 926 - 931, 2015.

6. G. I. Bhaskara and D. P. Sugiarti. Enhancing Cultural Heritage Tourism Experience with Augmented Reality Technology in Bali, E-Journal of Tourism, vol.6, no.1, pp. 102-118, 2019.

7. N. S. Mohd, H. N. Ismail and N. A. Halim. Mobile Augmented Reality: A Tool for Effective Tourism Interpretation in Enhancing Tourist Experience at Urban Tourism Destination, International Journal of Built Environment and Sustainability, vol. 2, no. 3, pp. 237-244, 2015.

8. A. Ć. Samardžija. Mobile Augmented Reality Interactive Systems for Urban Tourism, Central European Conference on Information and Intelligent System, September 23-25, 2015, pp. 129-134.

9. I. P. Sari and H. R. Fajrin. Mobile Augmented Reality Using Cloud Database for Interactive Museum Guiding System, Journal of Physics: Conference Series, vol. 1193 012030, 1-7, 2019.

10. D. Cianciarulo. From local traditions to "augmented reality". The MUVIG Museum of Viggiano (Italy), 
Heru Supriyono et al., International Journal of Emerging Trends in Engineering Research, 8(8), August 2020, 4293 - 4300

Procedia Social and Behavioral Sciences, vol. 188, pp. $138-143,2015$. https://doi.org/10.1016/j.sbspro.2015.03.349

11. N. Ghouaiel, S. Garbaya, J.-M. Cieutat and J.-P. Jessel. Mobile Augmented Reality in Museums : Towards Enhancing Visitor's Learning Experience, The International Journal of Virtual Reality, vol. 17, no. 1, pp. 21-31, 2016.

12. F. Vera, J. A. Sánchez and O. Cervantes. Enhancing User Experience in Points of Interest with Augmented Reality, International Journal of Computer Theory and Engineering, vol. 8, no. 6, pp. 450-457, December 2016.

13. A. Atsushi, T. Kitama, M. Toyoura and X. Mao. The Use of Augmented Reality Technology in Medical Specimen Museum Tours, Anatomical Sciences Education, vol. 12, pp. 561-571, 2019. https://doi.org/10.1002/ase.1822

14. Z. He, L. Wu and X. (R.) Li. When Art Meets Tech: The Role of Augmented Reality in Enhancing Museum Experiences and Purchase Intentions, Tourism Management, vol. 68, pp. 127-139, 2018.

15. M. Sharma. A study of SDLC to develop well engineered software, International Journal of Advanced Research in Computer Science, vol. 8, no. 3, pp. 520-523, 2017.

16. E. J. Baker, J. A. A. Bakar and A. N. Zulkifli. Elements of Museum Mobile Augmented Reality for Engaging Hearing Impaired Visitors, AIP Conference Proceedings, vol. 189, pp. 020033-1 - 020033-6, 2017.

17. H. Basin, E. Khanna and Sudha. Black Box Testing Based on Requirement Analysis and Design Specifications, International Journal of Computer Applications, vol. 87, no. 18, pp. 36-40, 2014.

18. R. G. Boboc, M. Duguleana, G.-D. Voinea, C.-C Postelnicu; D.-M. Popovici, and M. Carrozzino. Mobile Augmented Reality for Cultural Heritage: Following the Footsteps of Ovid among Different Locations in Europe, Sustainability 2019, vol. 11, 1167, 1-20, 2019.

19. H. Supriyono, R. F. Rahmadzani, and M. S. Adhantoro. Developing Computer Application for Interactive Javanese Letters Learning, International Journal of Advanced Trends in Computer Science and Engineering, vol. 8, no.6, pp. 3112-3119, November - December 2019.

20. N. Higgett, Y. Chen and E. Tatham. A User Experience Evaluation of the use of Augmented and Virtual Reality in Visualising and Interpreting Roman Leicester 210AD (Ratae Corieltavorum), Athens Journal of History, vol. 2, no. 1, pp. 7-22, 2016.

21. B. V. Priya, JKR Sastry. Assessment of Website Quality based on Appearance, International Journal of Emerging Trends in Engineering Research, volume 7, no. 10 , pp. 360-375, October 2019. https://doi.org/10.30534/ijeter/2019/017102019

22. S. Yadav, B. Kishan. Analysis and Assessment of Existing Software Quality Models to Predict the Reliability of Component-Based Software. International Journal of Emerging Trends in
Engineering Research, volume 8, no. 6, pp. 2824-2840, June 2020.

https://doi.org/10.30534/ijeter/2020/96862020

23. R. B. Jadhav, S. D. Joshi, U. G. Thorat, A. S. Joshi. Software Defect Prediction Utilizing Deterministic and Probabilistic Approach for Optimizing Performance through Defect Association Learning, International Journal of Emerging Trends in Engineering Research, volume 8, no. 6, pp. 2600-2605, June 2020.

https://doi.org/10.30534/ijeter/2020/62862020 